\title{
Chronic kidney disease care delivered by US family medicine and internal medicine trainees: results from an online survey Oliver Lenz* and Alessia Fornoni
}

\author{
Address: Division of Nephrology and Hypertension, University of Miami Miller School of Medicine, Miami, FL, USA \\ Email: Oliver Lenz* - olenz@med.miami.edu; Alessia Fornoni - afornoni@med.miami.edu \\ * Corresponding author
}

Published: 12 December 2006

BMC Medicine 2006, 4:30 doi:10.1186/174I-7015-4-30

This article is available from: http://www.biomedcentral.com/I74I-70I5/4/30

(c) 2006 Lenz and Fornoni; licensee BioMed Central Ltd.

This is an Open Access article distributed under the terms of the Creative Commons Attribution License (http://creativecommons.org/licenses/by/2.0), which permits unrestricted use, distribution, and reproduction in any medium, provided the original work is properly cited.
Received: 04 August 2006

Accepted: 12 December 2006

\begin{abstract}
Background: Complications of chronic kidney disease (CKD) contribute to morbidity and mortality. Consequently, treatment guidelines have been developed to facilitate early detection and treatment. However, given the high prevalence of CKD, many patients with early CKD are seen by non-nephrologists, who need to be aware of CKD complications, screening methods and treatment goals in order to initiate timely therapy and referral.
\end{abstract}

Methods: We performed a web-based survey to assess perceptions and practice patterns in CKD care among 376 family medicine and internal medicine trainees in the United States. Questions were focused on the identification of CKD risk factors, screening for CKD and associated comorbidities, as well as management of anemia and secondary hyperparathyroidism in patients with CKD.

Results: Our data show that CKD risk factors are not universally recognized, screening for CKD complications is not generally taken into consideration, and that the management of anemia and secondary hyperparathyroidism poses major diagnostic and therapeutic difficulties for trainees.

Conclusion: Educational efforts are needed to raise awareness of clinical practice guidelines and recommendations for patients with CKD among future practitioners.

\section{Background}

Complications of chronic kidney disease (CKD), such as anemia, metabolic acidosis, nutritional deficits, secondary hyperparathyroidism and hypertension occur well before renal replacement therapy is needed and significantly contribute to morbidity and mortality [1-5]. National treatment guidelines for CKD, and for the management of hypertension, dyslipidemia, bone disease, nutrition, anemia and cardiovascular disease in patients with CKD, have been published [6-12], and dedicated CKD clinics were established based on the conviction that such clinics would help implement Kidney Disease Out- comes Quality Initiative (KDOQI) goals and thus improve outcomes $[13,14]$. This belief was supported by the observation that patients with already-established advanced CKD who were referred late to a nephrologist had worse outcomes than those referred earlier $[15,16]$, and several groups of researchers [17-20] have postulated that CKD care could be improved by early detection, early referral, and a structured approach to CKD care. An analysis based on the National Health and Nutrition Examination Surveys (NHANES) III and Medicare databases showed that CKD care is suboptimal [21], and recent data suggests that primary care providers may not be familiar 
will KDOQI guidelines [22]. However, given the vast number of patients with CKD and the limited number of nephrologists $[23,24]$, most patients with early CKD are not seen by a nephrologist. Therefore, this web-based survey was designed to ascertain perceptions and practice patterns regarding CKD care in family medicine and internal medicine trainees.

\section{Methods \\ Study design}

The study was approved by the University of Miami's Human Subjects Research Office, protocol number 20060089, under the exempt category. This is a cross-sectional survey of family medicine and internal medicine trainees in the United States, conducted in February and March 2006. Attending physicians' responses served as a control group. The survey was designed to test practice patterns and was based on current KDOQI recommendations.

\section{Population}

Interns, residents, and fellows who were in training in family medicine or internal medicine residency programs in February or March 2006 within the United States were targeted for this survey. A group of attending physicians was included as a control group based on the hypothesis that their responses would provide an insight into the expected knowledge level of trainees at the end of their training.

\section{Inclusion criteria}

Physicians were included in the survey if they identified themselves as physicians practicing family or internal medicine.

\section{Exclusion criteria}

Excluded were respondents other than physicians (such as nurses or students), respondents whose primary specialty was not family or internal medicine, and respondents who did not provide any answer apart from demographics.

\section{Survey method}

The online survey instrument was critically reviewed by four experts in the field, administered to a focus group of five family medicine residents, and modified according to their suggestions. The survey was conducted in an anonymous fashion; no identifying data were retained. The sequence in which choices were presented for questions with multiple answers was randomized for each respondent. All answers except those about age and gender were required to advance in the survey. The survey instrument was posted online on February 1, 2006. Invitations to participate in the survey were distributed by email between February 17, 2006 and March 1, 2006 to 710 internal medicine and family medicine program directors across the United States. It was left up to the program director to decide whether or not to forward the invitation email to residents. A similar email was sent to attending physicians at the PI's center (University of Miami Miller School of Medicine, Miami, FL, USA) on March 3, 2006. The survey instrument was open for responses from February 17, 2006 to March 16, 2006. No incentive was offered for completion of the survey. A copy of the survey instrument is enclosed in Additional file 1. We also surveyed ten nephrology fellows and attendings to have an internal "positive control", and the data they provided are enclosed in Additional file 2.

\section{Statistical analysis}

Data are presented as descriptive statistics derived from cross-tabulation. Proportions were calculated based on the total number of respondents for each question and compared using Fisher's exact test assuming a normal distribution. Questions about risk factors were dichotomized into two groups, with those responding that the individual risk factor highly increases risk coded as yes and those responding that it does not or slightly increases risk coded as no. All analyses were carried out using SPSS 14.0 for Windows (SPSS Inc., Chicago, IL, USA). Area proportional Venn diagrams were constructed using the web-based application developed by S. Chow and P. Rodgers $[25,26]$.

\section{Results \\ Study population}

A total of 463 responses were received. A response rate could not be calculated given that the target population was not queried directly but through program directors. Fifty-one datasets were blank and were discarded; the remaining 412 data sets were retained for analysis. One hundred and sixty-two responses were received from family medicine trainees, 214 from internal medicine trainees, and 36 from attending physicians. Of the latter group, six were family practitioners, and 30 were internists. Among the internists there were one endocrinologist, one gerontologist, one oncologist, three infectious disease specialists, six cardiologists, and 18 general internists. Both trainees and attending physicians reported seeing a median of six patients with chronic kidney disease per week.

\section{Recognition of risk factors for chronic kidney disease and assessment of kidney function}

Participants were asked to rank a set of factors as increasing the risk for CKD "minimally", "moderately", or "highly". Answers were dichotomized, with "highly" being categorized as "yes" and the other two options as "no". The results are shown in Figure 1. The responses by family medicine and internal medicine trainees were not significantly different, and thus their responses were 


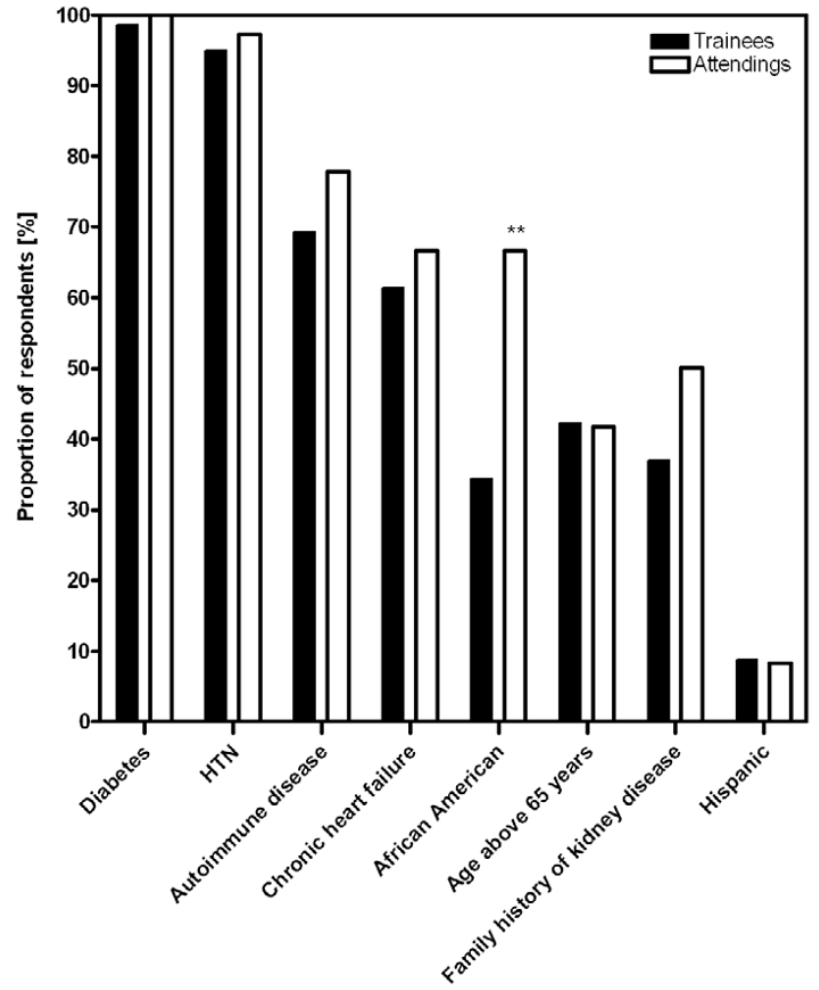

Figure I

Identification of risk factors for CKD. Shown is the proportion of respondents who stated that the shown conditions "highly" increase the risk to develop chronic kidney disease. HTN: hypertension. ${ }^{* *} \mathrm{p}<0.005$ (all trainees versus attendings).

pooled. Compared to trainees, a significantly higher proportion of attendings identified African-American race as a high risk to develop CKD ( $\mathrm{p}<0.005)$.

Participants were asked to identify the best method to estimated kidney function (Figure 2). Timed urine collection for creatinine was the most common choice, followed by estimated glomerular filtration rate (eGFR) using a mathematical formula. Compared to family medicine residents, a significantly higher proportion of internal medicine trainees, but not attending physicians, preferred eGFR over measured creatinine clearance $(\mathrm{p}<0.0001)$.

\section{Blood pressure goal and therapy choices}

The vast majority of respondents chose a blood pressure goal of less than 130/80 $\mathrm{mmHg}$ for a hypothetical patient with CKD and a creatinine clearance of $40 \mathrm{ml} / \mathrm{min}$ (Figure $3 \mathrm{~A})$. The question posed was: "Which class of antihypertensive medication was considered a first-line agent to slow the progression of kidney disease in a patient with mild to moderate CKD?" (Figure 3B). The responses from

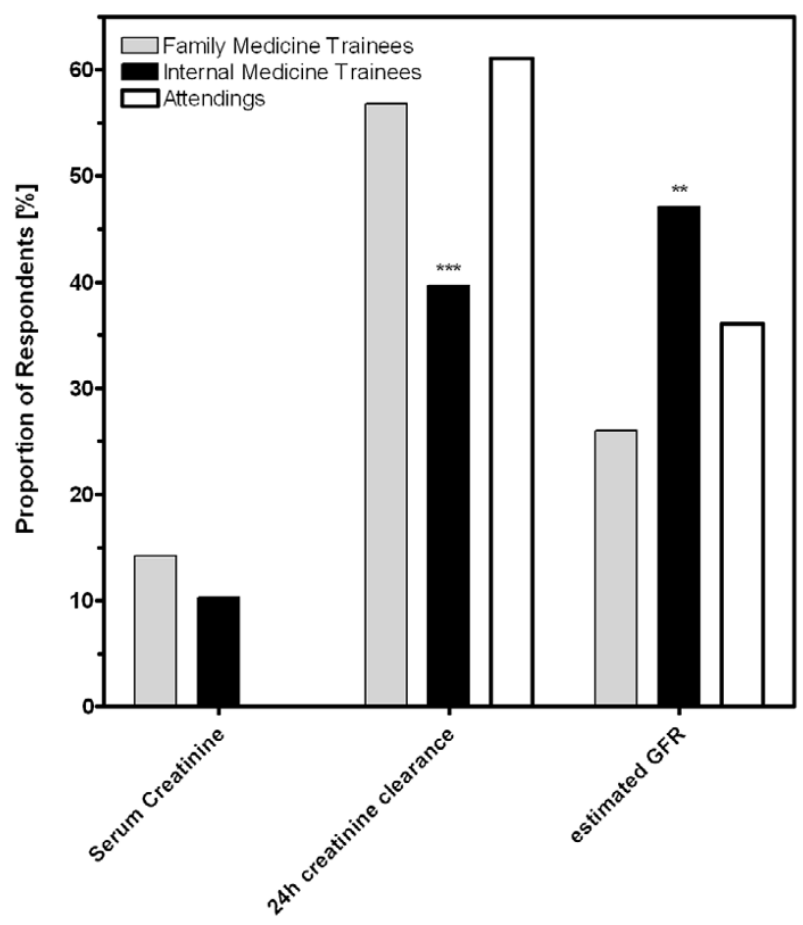

Figure 2

Evaluating kidney function. Shown is the proportion of respondents who identified serum creatinine, measured creatinine clearance, or estimated glomerular filtration rate (GFR), respectively, as the best method to evaluate kidney function. $* *_{p}<0.005 ; * * *_{p}<0.0005$ (family medicine versus internal medicine trainees).

family medicine trainees, internal medicine trainees, and attendings were not statistically different for the data shown in Figures $3 \mathrm{~A}, \mathrm{~B}$, and were therefore pooled. Angiotensin-converting enzyme inhibitors (ACEi) or angiotensin receptor blockers (ARB) were the first-line medications chosen by $90 \%$ and $48 \%$ of respondents, respectively, and only $6 \%$ chose neither of the two. Respondents were then given a case scenario of a 37-yearold man with hypertension, microalbuminuria, and a blood pressure of $145 / 95 \mathrm{mmHg}$, who is only treated with a thiazide diuretic. Asked if they would add an ACEi to this patient's regimen, a decreasing number of respondents opted to do so as the patient's serum creatinine increased (Figure 3C). Family medicine trainees were significantly less likely to choose an ACEi once the serum creatinine was greater than $1.4 \mathrm{mg} / \mathrm{dl}(\mathrm{P}<0.0001)$. There was no difference in the response whether the scenario was given for an African-American or a Non-Hispanic Caucasian man (data not shown). 

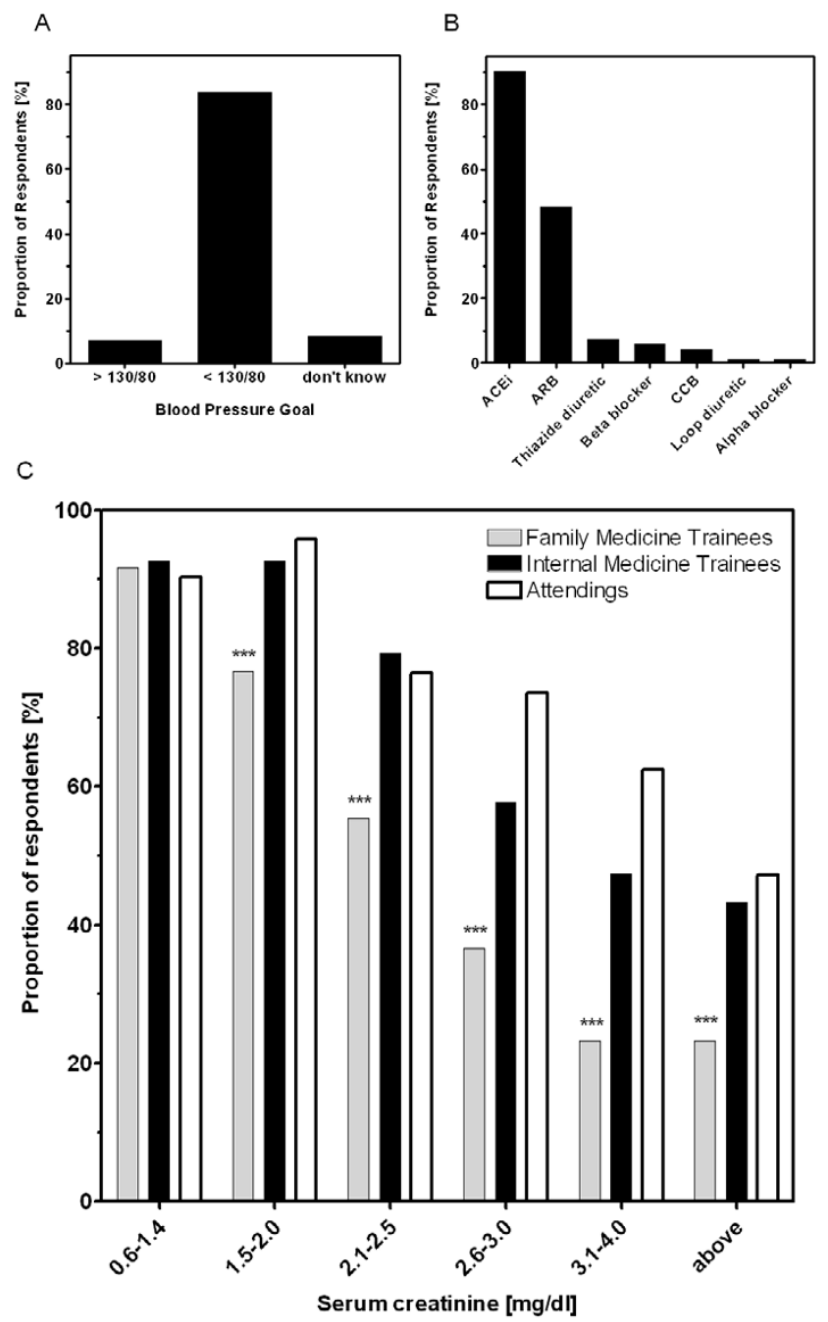

Figure 3

Blood pressure management in CKD patients. Panel $A$ shows the blood pressure goals chosen for patients with stage 3 CKD. Panel B shows the classes of antihypertensive agents identified as first-line therapy to slow the progression of renal failure in patients with mild to moderate renal impairment. For panels $A$ and $B$, data were pooled from all respondents as no differences were found between trainees' or attendings' responses. Panel $\mathrm{C}$ shows the proportion of respondents who would add an angiotensin converting enzyme inhibitor to the regimen of a hypertensive patient with microalbuminuria currently treated with a thiazide diuretic, as a function of the patient's serum creatinine. ${ }^{* * *} \mathrm{p}<$ 0.005 for family medicine versus internal medicine trainees and $p<0.05$ for family medicine trainees versus attendings. $p$ $>0.05$ for internal medicine trainees versus attendings.

\section{Complications of CKD}

When asked what conditions were complications of CKD, more than $80 \%$ of all respondents recognized worsening hypertension, anemia, hyperkalemia, and volume overload. A smaller proportion of family medicine residents than internal medicine trainees chose metabolic acidosis (76\% vs $85 \%, \mathrm{P}<0.05)$ and secondary hyperparathyroidism (SHP; $61 \%$ vs $86 \%, \mathrm{P}<0.0001$ ). A smaller proportion of trainees identified malnutrition $(47 \%$ and $54 \%$ ) and dyslipidemia (32\% and $42 \%$ ) as CKD complications. The proportion of attendings was higher than the proportion of trainee for any of the choices (Figure 4A). A case scenario of a 55-year-old African-American woman with hypertension, type 2 diabetes, and a last known serum creatinine of $2 \mathrm{mg} / \mathrm{dl}$, was given. The question was posed: "Which of the following laboratory tests would you order in a patient like this?" in order to determine what complications trainees were likely to screen for (Figure 4B). Seventy percent of all respondents requested microalbumin in a random urine sample, but only $19 \%$, $37 \%$, and $23 \%$ of family medicine trainees, internal medicine trainees and attendings, respectively, concomitantly requested a urine creatinine. Although more than $80 \%$ of trainees identified anemia as a complication of CKD, only $36 \%$ requested a complete blood count in this hypothetical patient with stage 3 CKD. Screening for SHP and nutrition reflected the low rates of recognition shown in the prior question (Figure 4A). Moreover, when screening for SHP, $10 \%, 21 \%$ and $20 \%$ of family medicine trainees, internal medicine trainees, and attendings, respectively, only requested serum calcium and serum phosphate, and only $6 \%, 19 \%$, and $23 \%$, respectively, requested a parathyroid hormone ( $\mathrm{p}=0.002$ for family versus internal medicine trainees), either alone $(1 \%, 5 \%, 10 \%)$ or together with calcium and phosphate $(5 \%, 14 \%, 13 \%)$. All except two attendings (94\%) indicated that they would request A1c, while only $74 \%$ of trainees did so $(\mathrm{P}<0.0005)$. A similar discrepancy between attendings and trainees was seen for the lipid panel $(75 \%$ vs $48 \%$, p < 0.005$)$.

\section{Anemia and secondary hyperparathyroidism}

Three additional questions concerning screening and management of anemia and SHP were posed: (1) is it a complication of CKD;(2) at what stage of CKD do you screen for it; and (3) at what level of hemoglobin (Hgb) or parathyroid hormone (PTH), respectively, do you start therapy or ask for a consultation when faced with a patient whose creatinine clearance is $40 \mathrm{ml} / \mathrm{min}$. Only respondents who answered all three questions were included in the analysis $(\mathrm{N}=312)$. Data from all respondents, family and internal medicine trainees and attendings, were pooled for this analysis and represented as area proportional Venn diagrams (Figure 5). In each diagram, area $\mathrm{A}$ represents the proportion of respondents who identified the condition as a complication of CKD, area $\mathrm{B}$ 
A

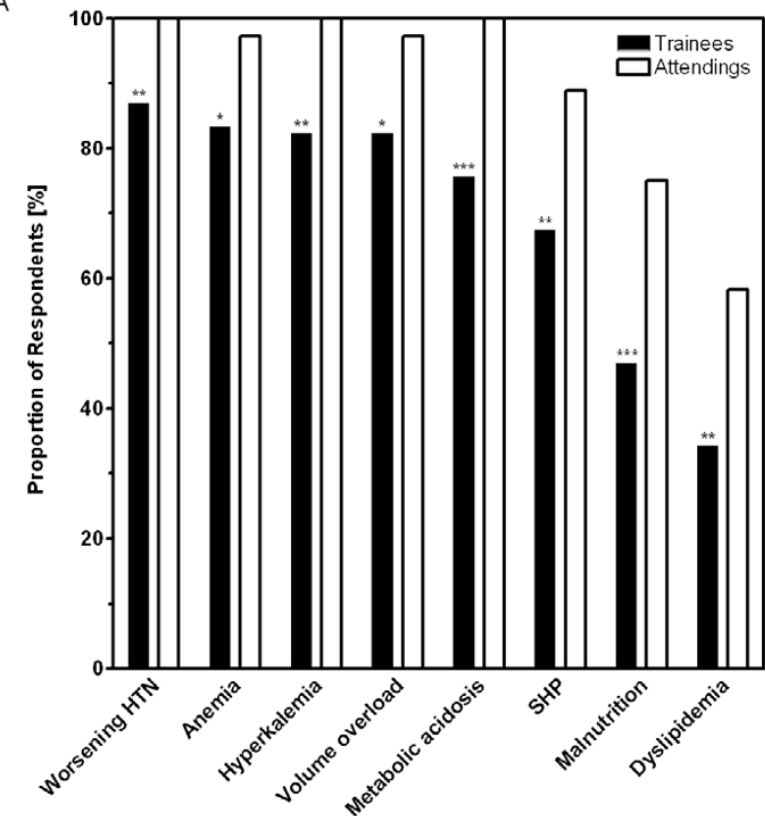

B

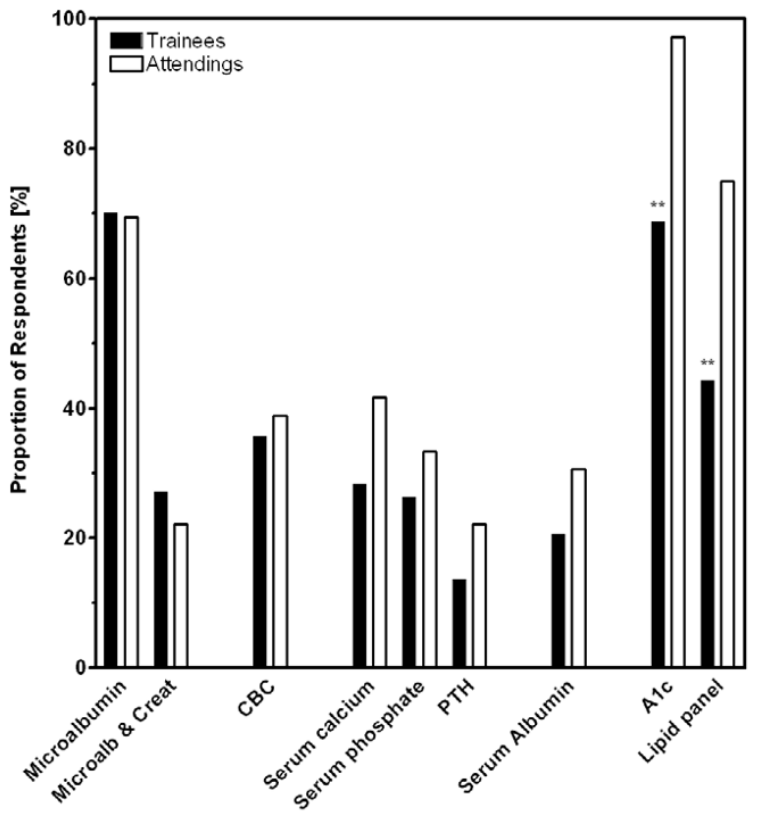

Figure 4

Complications of CKD. Panel A shows the proportion of respondents who identified the listed conditions as co-morbidities of CKD (*p $<0.05$; **p $<0.01$; ***p $<0.005$ for trainees versus attendings). Panel $B$ shows the proportion of respondents who would order the listed laboratory data in a hypothetical patient ( 55 year-old African American woman with diabetes, hypertension, and a serum creatinine of $2 \mathrm{mg} /$ $\mathrm{dl})$. Data for family medicine and internal medicine were pooled because the two groups were not different from each other. ${ }^{* *} \mathrm{p}<0.01$ for trainees versus attendings. indicates the proportion of respondents screening for the condition in stage $3 \mathrm{CKD}$ or earlier, and area $\mathrm{C}$ shows the proportion of respondents who started therapy or asked for a consult at a Hgb $<11 \mathrm{~g} / \mathrm{dl}$ or a PTH $>70 \mathrm{ng} / \mathrm{ml}$, respectively. Among all respondents, 92\% identified anemia as a complication of CKD, 55\% indicated that they would screen at stage 3 CKD or earlier, and $15 \%$ would intervene at a hemoglobin of less than $11 \mathrm{~g} / \mathrm{dl}$ in a patient with a creatinine clearance of $40 \mathrm{ml} / \mathrm{min}$, resulting in only $11 \%$ of respondents who correctly integrated all three parameters. Similar results were seen for SHP management, with only $15 \%$ of respondents identifying SHP as a CKD complication, screening at CKD stage 3 or earlier, and intervening once intact PTH surpasses $70 \mathrm{ng} / \mathrm{ml}$ in a patient with a creatinine clearance of $40 \mathrm{ml} / \mathrm{min}$.

\section{Discussion}

Delayed referral of CKD patients to a nephrologist has been identified as an important predictor of poor outcomes $[15,16]$. However, in order to initiate timely referral of CKD patients, primary providers need to be aware of risk factors for CKD and co-morbidities associated with $\mathrm{CKD}$, as well as clinical practice guidelines describing optimal CKD care, such as KDOQI guidelines, the recently-published recommendations from the American Diabetes Association (ADA) [27], or the clinical practice guidelines developed by the Renal Physicians Association [28], the latter being published as an executive summary with clear "hands-on" guidance as to the management of patients with an estimated GFR of less than $30 \mathrm{ml} / \mathrm{min} /$ $1.73 \mathrm{~m}^{2}$. Several educational efforts are currently under way to enhance awareness of CKD $[29,30]$. However, the data presented in this report show that both family medicine and internal medicine trainees have important knowledge gaps when it comes to CKD care.

Similar to data recently published by Lea et al [22], almost all physicians identified diabetes and hypertension as strong risk factors, while minority status or family history did not receive the same recognition. This may be due to the absence of a unifying model predicting CKD risk in the general population [31]. Some risk factors, such as diabetes and hypertension, have clearly been established [32]. However, attempts to quantitate the contribution of others, such as race, ethnicity, and socio-economic status, has proven to be more challenging because of the varying prevalence of co-morbid diseases such as hypertension [33-35]. In addition, the prevalence of CKD among different racial and ethnic groups may vary according to the stage of CKD [36]. Thus, it may be necessary to perform and pool data from large, population-based studies to further delineate the contribution of individual CKD risk factors $[37,38]$, allowing primary providers to screen for CKD akin to cardiovascular risk assessment based on the Framingham Study [39]. 

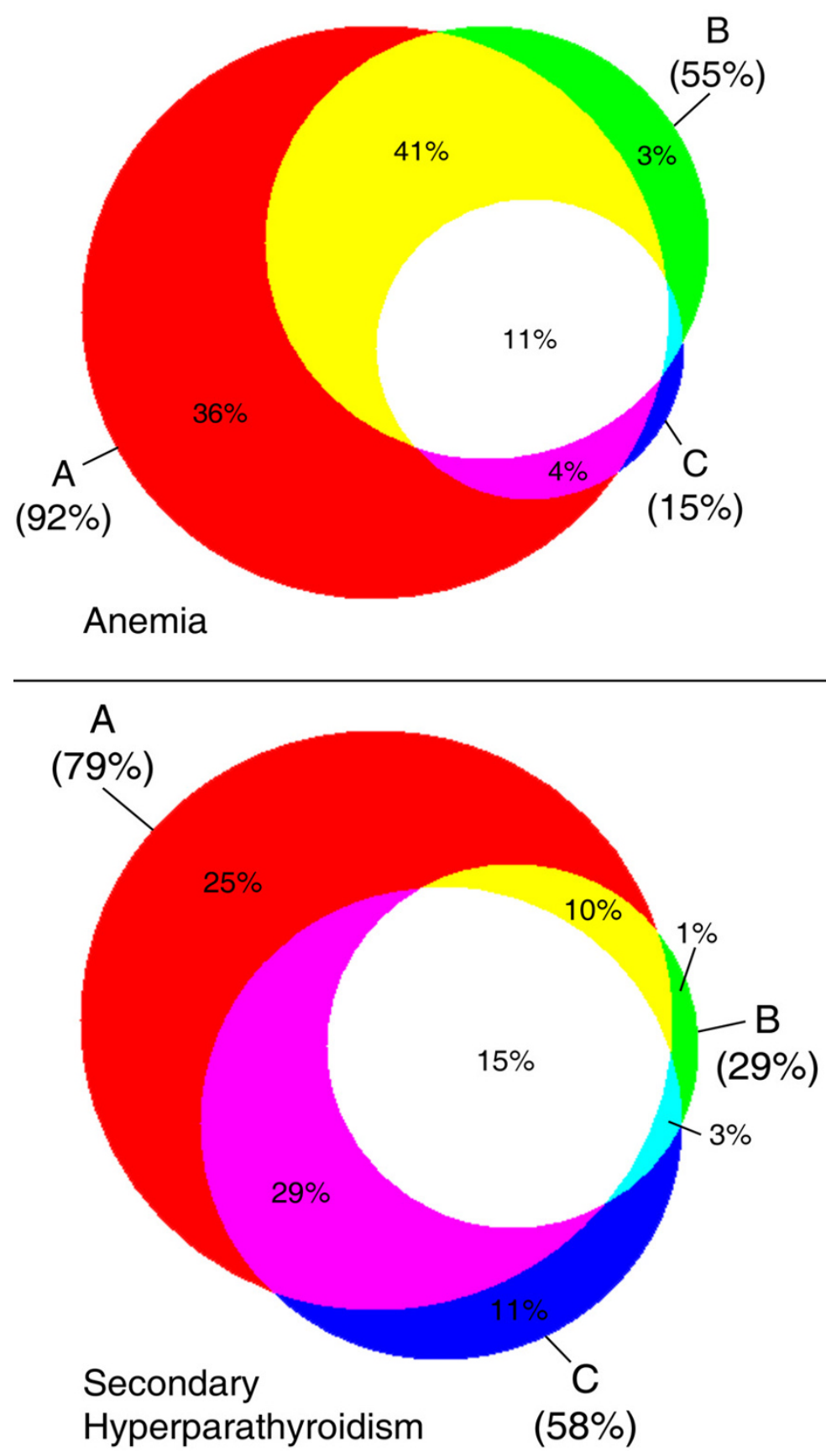

\section{Figure 5}

Management of anemia and secondary hyperparathyroidism. The top panel shows the proportion of respondents who indicated that anemia is a complication of CKD (A, 92\%), that they screened starting in stage 3 CKD or earlier (B, 55\%), and that they intervened at a hemoglobin concentration of less than II g/dl (C, I5\%). Overlapping areas correspond to the proportion of participants whose responses fulfilled two adjacent or all three criteria (white, II\%); the two blue areas correspond to less than $1 \%$ each. The bottom panel shows the proportion of respondents who indicated that secondary hyperparathyroidism is a complication of CKD (A, 79\%), that they screened starting in stage 3 CKD or earlier (B, 29\%), and that they intervened at an intact PTH concentration of more than $70 \mathrm{pg} / \mathrm{ml}(\mathrm{C}, 58 \%)$. Overlapping areas correspond to the proportion of participants whose responses fulfilled two adjacent or all three criteria (white, $15 \%$ ). 
The use of mathematical formulas to estimate GFR rather than a timed urine collection for creatinine clearance is recommended for most patients [40], and the examination of a random urine sample for albumin and creatinine is the preferred screening method for albuminuria in adults $[7,27]$. However, despite this, more than half the physicians preferred a timed urine collection for creatinine, and in a hypothetical patient with diabetes and stage $3 \mathrm{CKD}$, only $70 \%$ of physicians elected to screen for microalbuminuria. Moreover, among those who did screen for microalbuminuria, only about a third would concomitantly obtain a urine creatinine concentration to normalize the albumin result (family medicine trainees: $19 \%$, internal medicine trainees: $37 \%$ ), as recommended by both the NKF and ADA [27,41]. Thus, further emphasis may need to be placed on hands-on implementation of clinical practice guidelines to improve the detection of subjects with CKD.

The vast majority of respondents identified blood pressure goal and first line antihypertensive agents for patients with CKD as recommended by the Seventh Report of the Joint National Committee on Prevention, Detection, Evaluation, and Treatment of High Blood Pressure [42]. However, practitioners, and in particular family medicine residents, were hesitant to use ACEi in the setting of stage 3 or 4 CKD. Data supporting the use of ACEi and ARB show that these agents are not only beneficial in patients with an abnormal serum creatinine, but also safe, as long as patients are carefully monitored and counseled $[43,44]$. Thus, it may be necessary to not only disseminate information about the usefulness of a given intervention, but also hands-on information about monitoring, prevention, and treatment of potential complications.

Almost all physicians recognized worsening hypertension, anemia, hyperkalemia, volume overload, and metabolic acidosis as complications of CKD. However, secondary hyperparathyroidism, malnutrition, and lipid disorders were identified by a significantly smaller proportion of respondents. Moreover, even though about $90 \%$ of physicians recognized anemia as a complication of CKD, only about $40 \%$ indicated that they would obtain a CBC in a hypothetical patient with diabetes and an eGFR of $34 \mathrm{ml} / \mathrm{min} / 1.73 \mathrm{~m}^{2}$. Similarly, even among those who identified secondary hyperparathyroidism as a CKD complication, only a small fraction would order the appropriate screening test. This reflects the observation that the majority of patients with stage 4 CKD referred to a nephrologist were never screened for secondary hyperparathyroidism and had lower hemoglobin concentrations than those seen in a dedicated CKD clinic for at least six months [45]. In addition, the management of anemia and secondary hyperparathyroidism requires complex decision-making. These disorders have not only to be recog- nized as a complication of CKD, but in order to avoid future complications, screening needs to be initiated in stage 3 CKD and physicians also need to know about recommended treatment targets in order to either initiate therapy or consult an experienced specialist $[9,12]$. The data from this survey show that no more than $10 \%$ of physicians had the skills to integrate data from all three areas correctly, allowing them to formulate appropriate management plans for CKD patients with anemia or secondary hyperparathyroidism. Thus, unless an educational effort aimed specifically at non-nephrologists fills these knowledge gaps, nephrologists will likely have to co-manage patients with stage 3 and 4 CKD.

Clinical practice guidelines may present treatment goals, but often lack the necessary guidance as to why and how to reach these goals. Recently, an approach to link evidence with practice in CKD care, which may be particularly useful in managed care settings, has been published [46]; however, none of the strategies to improve compliance tested thus far have proven fail-safe [47]. Deficits in compliance with clinical practice guidelines are not unique to nephrology, and the reasons for non-compliance are complex [48]. Recent data show that there is an acute lack of awareness of clinical practice guidelines for CKD patients among primary providers $[22,49]$. Based on the data presented here, educational efforts aimed at improving CKD care will have to start during the training program, even though this may be a challenging undertaking given the requirements and restrictions placed upon US training programs [50]. Specifically, trainees will need to be instructed about prevalence of CKD, risk factors for CKD, screening methods for CKD and its complications, and treatment options to slow the progression of CKD and reduce morbidity and mortality [51-54]. In order to succeed, guidelines will have to be presented in a manner that fosters reflection, critically appraises clinical evidence, is practice-based, and is easy to understand for practitioners and patients alike $[48,55]$.

This study has several important limitations. Given that it is based on a voluntary, anonymous online survey, certain important variables, such as training program size and setting, or the presence or absence of formal teaching in CKD care, cannot be controlled. In addition, demographic characteristics of the study cohort cannot be verified. Finally we cannot be certain that the answers truly reflect the knowledge of the person completing the survey, given that the survey instrument has not been formally validated in this respect, although we did include nephrologists who might serve as a positive control group (see Additional file 2). However, given that we received a large number of responses from across the United States, we believe that the data presented here are representative and 
covey important information about practice patterns of future providers.

\section{Conclusion}

In conclusion, the results from this survey suggest that physicians currently in training have significant knowledge gaps in CKD management, and with few exceptions attendings' responses closely mimicked those of trainees. These finding suggests that education is needed to raise awareness of clinical practice guidelines and recommendations for patients with CKD among future practitioners. Surveys similar to ours may be useful in the planning of training programs to assess areas that need additional emphasis.

\section{Competing interests}

Oliver Lenz has received educational grants, honoraria, and consulting fees from Abbott Laboratories, Amgen, Genzyme, OrthoBiotech, and Pfizer.

\section{Authors' contributions}

Oliver Lenz designed, published, and analyzed the survey and wrote the manuscript. Alessia Fornoni assisted in the design of the survey and co-wrote the manuscript.

\section{Additional material}

\section{Additional file 2}

\section{Summary of responses by nephrologists}

The survey instrument was administered to ten nephrology fellows and attending physicians at the investigators' center. Their answers served as a reference as to what to expect from a (presumably) knowledgeable population. All nephrology fellows had completed formal theoretical and practical training in CKD care.

Click here for file.

[http://www.biomedcentral.com/content/supplementary/1741-

7015-4-30-S2.pdf]

\section{Additional File 1}

\section{Survey Instrument}

The survey instrument was administered as shown except that a random sequence was chosen for the options in items 7, 8, 10, 11, 12, 17 and 18 whenever a survey was begun.

Click here for file

[http://www.biomedcentral.com/content/supplementary/1741-

7015-4-30-S1.pdf]

\section{Acknowledgements}

The author wishes to thank Drs W. Kupin, B. Materson, D. Roth, and I. Schulman for critically reviewing the survey instrument, and E. Davila for assistance with the statistical analyses.

\section{References}

I. Collins AJ: Anaemia management prior to dialysis: cardiovascular and cost-benefit observations. Nephrol Dial Transplant Supp/ 2003, 18:ii2-ii6.
2. Xue JL, St Peter WL, Ebben JP, Everson SE, Collins AJ: Anemia treatment in the pre-ESRD period and associated mortality in elderly patients. Am J Kidney Dis 2002, 40: I I53-II6I.

3. Eustace JA, Astor B, Muntner PM, Ikizler TA, Coresh J: Prevalence of acidosis and inflammation and their association with low serum albumin in chronic kidney disease. Kidney Int 2004, 65:1031-1040.

4. Locatelli F, Pozzoni P, Tentori F, del Vecchio L: Epidemiology of cardiovascular risk in patients with chronic kidney disease. Nephrol Dial Transplant Suppl 2003, I 8:vii2-vii9.

5. John R, Webb M, Young A, Stevens PE: Unreferred chronic kidney disease: a longitudinal study. Am J Kidney Dis 2004, 43:825-835.

6. K/DOQI NKF: Clinical practice guidelines for nutrition in chronic renal failure. Am J Kidney Dis 2000, 35:SI-SI40.

7. K/DOQI NKF: Clinical practice guidelines for chronic kidney disease: evaluation, classification and stratification. Am J Kidney Dis 2002, 39:SI-S266.

8. K/DOQI NKF: Clinical practice guidelines for management of dyslipidemias in patients with kidney disease. Am J Kidney Dis 2003, 4I:SI-S9I.

9. K/DOQI NKF: Clinical practice guidelines for bone metabolism and disease in chronic kidney disease. Am J Kidney Dis 2003, 42:SI-S202.

10. K/DOQI NKF: Clinical practice guidelines on hypertension and antihypertensive agents in chronic kidney disease. $\mathrm{Am} J$ Kidney Dis 2004, 43:SI-S290.

II. K/DOQI NKF: Clinical practice guidelines for cardiovascular disease in dialysis patients. Am J Kidney Dis 2005, 45:SI-I 53.

12. K/DOQI NKF: Clinical practice guidelines and clinical practice recommendations for anemia of chronic kidney disease. Am J Kidney Dis 2006, 47:SI-SI45.

13. St Peter WL, Schoolwerth AC, McGowan T, McClellan WM: Chronic kidney disease: issues and establishing programs and clinics for improved patient outcomes. Am J Kidney Dis 2003, $41: 903-924$.

14. Ghossein C, Serrano A, Rammohan M, Batlle D: The role of comprehensive renal clinic in chronic kidney disease stabilization and management: the Northwestern experience. Semin Nephrol 2002, 22:526-532.

15. Arora P, Obrador GT, Ruthazer R, Kausz AT, Meyer KB, Jenuleson CS, Pereira BJ: Prevalence, predictors, and consequences of late nephrology referral at a tertiary care center. I Am Soc Nephrol 1999, 10:128I-1286.

16. Stack AG: Impact of timing of nephrology referral and preESRD care on mortality risk among new ESRD patients in the United States. Am J Kidney Dis 2003, 4I:310-3I8.

17. Pereira BJ: Optimization of pre-ESRD care: the key to improved dialysis outcomes. Kidney Int 2000, 57:35I-365.

18. Levin A, Lewis M, Mortiboy P, Faber S, Hare I, Porter EC, Mendelssohn DC: Multidisciplinary predialysis programs: quantification and limitations of their impact on patient outcomes in two Canadian settings. Am J Kidney Dis 1997, 29:533-540.

19. Goldstein M, Yassa T, Dacouris N, McFarlane P: Multidisciplinary predialysis care and morbidity and mortality of patients on dialysis. Am J Kidney Dis 2004, 44:706-7I4.

20. Khan SS, Xue JL, Kazmi WH, Gilbertson DT, Obrador GT, Pereira BJ, Collins AJ: Does predialysis nephrology care influence patient survival after initiation of dialysis? Kidney Int 2005, 67:1038-1046.

21. Owen WF Jr: Patterns of care for patients with chronic kidney disease in the United States: dying for improvement. J Am Soc Nephrol 2003, I4:S76-S80.

22. Lea JP, McClellan WM, Melcher C, Gladstone E, Hostetter T: CKD risk factors reported by primary care physicians: do guidelines make a difference? Am J Kidney Dis 2006, 47:72-77.

23. Troidle L, Smith GO: Can physician assistants fill the gaps in the nephrology workforce? Nephrol News Issues 2005, 19:65-67.

24. Steinman TI: Nephrology workforce shortfall: solutions are needed. Am J Kidney Dis 1999, 33:798-800.

25. Chow S, Rodgers P: Constructing area-proportional Venn and Euler diagrams with three circles [Abstract]. INRIA Rocquencourt: Euler Diagrams Workshop, Paris; 2005.

26. Chow S, Rodgers P: Applet for drawing 3 setarea-proportional Venn diagrams. [http://www.cs.kent.ac.uk/people/staff/pjir/Euler VennCircles/EulerVennApplet.html]. 
27. American Diabetes Association: Standards of medical care in diabetes - 2006. Diabetes Care 2006, 29(SuppI I):S4-42.

28. Bolton WK: Renal physicians association clinical practice guideline: appropriate patient preparation for renal replacement therapy: guideline number 3. J Am Soc Nephrol 2003 |4:|406-1410.

29. National Institutes of Diabetes Digestive andKidney Diseases: National Kidney Disease Education Program [http:// nkdep.nih.gov/]

30. K/DOQI NKF: Kidney learning system. [http://www.kidney.org/ professionals/KLS/index.cfm].

31. McClellan WM, Flanders WD: Risk factors for progressive chronic kidney disease. J Am Soc Nephrol 2003, I 4:S65-S70.

32. USRDS 2005 Annual Data Report: Atlas of end-stage renal disease in the United States. [http://www.usrds.org/atlas.htm]

33. McClellan W, Tuttle E, Issa A: Racial differences in the incidence of hypertensive end-stage renal disease (ESRD) are not entirely explained by differences in the prevalence of hypertension. Am J Kidney Dis 1988, I 2:285-290.

34. Whittle JC, Whelton PK, Seidler AJ, Klag MJ: Does racial variation in risk factors explain black-white differences in the incidence of hypertensive end-stage renal disease? Arch Intern Med |99|, | 5 |:|359-|364.

35. Tarver-Carr ME, Powe NR, Eberhardt MS, LaVeist TA, Kington RS, Coresh J, Brancati FL: Excess risk of chronic kidney disease among African-American versus white subjects in the United States: a population-based study of potential explanatory factors. I Am Soc Nephrol 2002, 13:2363-2370.

36. McClellan W, Warnock DG, McClure L, Campbell RC, Newsome BB Howard V, Cushman M, Howard G: Racial differences in the prevalence of chronic kidney disease among participants in the Reasons for Geographic and Racial Differences in Stroke (REGARDS) cohort study. J Am Soc Nephrol 2006, I 7: I710-17I5

37. Haroun MK, Jaar BG, Hoffman SC, Comstock GW, Klag MJ, Coresh J: Risk factors for chronic kidney disease: a prospective study of 23,534 men and women in Washington County, Maryland. J Am Soc Nephrol 2003, I 4:2934-294 I.

38. Iseki K, Iseki C, Ikemiya Y, Fukiyama K: Risk of developing endstage renal disease in a cohort of mass screening. Kidney Int 1996, 49:800-805.

39. Linton MF, Fazio S: A practical approach to risk assessment to prevent coronary artery disease and its complications. Am Cardiol 2003, 92: 19i-26i.

40. Stevens LA, Coresh J, Greene T, Levey AS: Assessing kidney function - measured and estimated glomerular filtration rate. $N$ Engl J Med 2006, 354:2473-2483.

41. Keane WF, Eknoyan G: Proteinuria, albuminuria, risk, assessment, detection, elimination (PARADE): a position paper of the National Kidney Foundation. Am J Kidney Dis 1999 33:1004-1010

42. Chobanian AV, Bakris GL, Black HR, Cushman WC, Green LA, Izzo JL Jr, Jones DW, Materson BJ, Oparil S, Wright JT Jr, Roccella EJ: Seventh report of the Joint National Committee on Prevention, Detection, Evaluation, and Treatment of High Blood Pressure. Hypertension 2003, 42: I 206- 1252.

43. Bloom JM: Benazepril for advanced chronic renal insufficiency. N Engl J Med 2006, 354:|530-I53I.

44. Mann JF, Gerstein HC, Pogue J, Bosch J, Yusuf S: Renal insufficiency as a predictor of cardiovascular outcomes and the impact of ramipril: the HOPE randomized trial. Ann Intern Med 200I, I34:629-636.

45. Lenz O, Mekala DP, Patel DV, Fornoni A, Metz D, Roth D: Barriers to successful care for chronic kidney disease. BMC Nephrol 2005, 6: II

46. Matchar DB, Patwardhan MB, Samsa GP, Haley WE: Facilitated process improvement: an approach to the seamless linkage between evidence and practice in CKD. Am J Kidney Dis 2006, 47:528-538.

47. Bero LA, Grilli R, Grimshaw JM, Harvey E, Oxman AD, Thomson MA Closing the gap between research and practice: an overview of systematic reviews of interventions to promote the implementation of research findings. The Cochrane Effective Practice and Organization of Care Review Group. BMJ I998, 3 I 7:465-468.

48. Baker R: Is it time to review the idea of compliance with guidelines? $\mathrm{Br} J$ Gen Pract 200 I, 5 I:7.
49. Boulware LE, Troll MU, Jaar BG, Myers DI, Powe NR: Identification and referral of patients with progressive CKD: a national study. Am J Kidney Dis 2006, 48: 192-204

50. Charap $\mathrm{MH}$, Levin RI, Pearlman RE, Blaser MJ: Internal medicine residency training in the 2 I st century: aligning requirements with professional needs. Am J Med 2005, I I 8: I 042- 046.

5I. Nissenson AR, Agarwal R, Allon M, Cheung AK, Clark W, Depner T, Diaz-Buxo JA, Kjellstrand C, Kliger A, Martin KJ, Norris K, Ward R, Wish J: Improving outcomes in CKD and ESRD patients: carrying the torch from training to practice. Semin Dial 2004, I 7:380-397

52. Hostetter T, Gladstone EH, Sica DA: National Kidney Disease Education Program in 2004: a program in evolution. J Clin Hypertens (Greenwich) 2004, 6:299-302.

53. Pereira BJ: Overcoming barriers to the early detection and treatment of chronic kidney disease and improving outcomes for end-stage renal disease. Am J Manag Care 2002 8:SI22-SI35.

54. Kliger AS, Haley WE: Clinical practice guidelines in end-stage renal disease: a strategy for implementation. J Am Soc Nephrol 1999, 10:872-877.

55. Peile E: Is it time to review the idea of compliance with guidelines? Br / Gen Pract 200 I, 5 I:229.

\section{Pre-publication history}

The pre-publication history for this paper can be accessed here:

http://www.biomedcentral.com/1741-7015/4/30/prepub
Publish with Bio Med Central and every scientist can read your work free of charge

"BioMed Central will be the most significant development for disseminating the results of biomedical research in our lifetime. "

Sir Paul Nurse, Cancer Research UK

Your research papers will be:

- available free of charge to the entire biomedical community

- peer reviewed and published immediately upon acceptance

- cited in PubMed and archived on PubMed Central

- yours - you keep the copyright
BiolMedcentral 